\begin{tabular}{|c|l|}
\hline Title & Cytosolic chaperonin prevents polyglutamine toxicity with altering the aggregation state. \\
\hline Author(s) & $\begin{array}{l}\text { Kitamura, A kira; Kubota, Hiroshi; Pack, Chan-Gi; Matsumoto, Gen; Hiray ama, Shoshiro; Takahashi, Y asuo; Kimura, } \\
\text { Hiroshi; Kinjo, Masataka; Morimoto, Richard; Nagata, Kazuhiro }\end{array}$ \\
\hline Citation & $\begin{array}{l}\text { Nature cell biology, 8(10), 1163_1169 } \\
\text { https://doi.org/10.1038/hcb1478 }\end{array}$ \\
\hline Issue Date & $2006-12$ \\
\hline Doc URL & http://hdl.handle.net/2115/57990 \\
\hline Type & article(author version) \\
\hline File Information & NCB_Final_Kitamura_MS.pdf \\
\hline
\end{tabular}

Instructions for use 


\title{
Cytosolic chaperonin prevents polyglutamine toxicity with altering the aggregation state
}

\author{
Akira Kitamura $^{1}$, Hiroshi Kubota ${ }^{1,6}$, Chan-Gi Pack², Gen Matsumoto ${ }^{3}$, Shoshiro \\ Hirayama $^{1}$, Yasuo Takahashi ${ }^{2,4}$, Hiroshi Kimura ${ }^{5}$, Masataka Kinjo ${ }^{2}$, Richard I. \\ Morimoto $^{3}$ and Kazuhiro Nagata ${ }^{1}$
}

${ }^{1}$ Department of Molecular and Cellular Biology and CREST/JST, Institute for Frontier Medical Sciences, Kyoto University, 53 Shogoin Kawahara-cho, Sakyo-ku, Kyoto 606-8397, Japan.

${ }^{2}$ Laboratory of Supramolecular Physics, Research Institute for Electronic Science, Hokkaido University, N12W6, Kita-ku, Sapporo, 060-0812, Japan.

${ }^{3}$ Department of Biochemistry, Molecular Biology and Cell Biology, Rice Institute for Biomedical Research, Northwestern University, Evanston, IL 60208, USA.

${ }^{4}$ Olympus Corporation, 2-3 Kuboyama-cho, Hachioji-shi, Tokyo 192-8512, Japan

${ }^{5}$ Nuclear Function and Dynamics Unit, HMRO, School of Medicine, Kyoto University, Yoshida Konoe-cho, Sakyo-ku, Kyoto 606-8501, Japan.

${ }^{6}$ Correspondence should be addressed to H.K. (e-mail: hkubota@frontier.kyoto-u.ac.jp) 
Polyglutamine (polyQ)-expansion proteins cause neurodegenerative disorders including Huntington's disease, Kenndy's disease, and various ataxias. The cytotoxicity of these proteins is associated with the formation of aggregates or other conformationally toxic species. Here we show that the cytosolic chaperonin CCT/TRiC can alter the course of aggregation and cytotoxicity of huntingtin (htt)/polyQ proteins in mammalian cells. Disruption of the CCT/TRiC complex by RNAi-mediated knockdown enhanced htt/polyQ aggregate formation and cellular toxicity. Analysis of the aggregation states of the htt/polyQ proteins by fluorescence correlation spectroscopy revealed that CCT/TRiC depletion results in the appearance of soluble htt/polyQ aggregates. Likewise, overexpression of all eight subunits of CCT/TRiC suppressed htt aggregation and neuronal cell death. These results indicate that $\mathrm{CCT} / \mathrm{TRiC}$ has an essential protective role from the cytotoxicity of polyQ proteins by affecting the course of aggregation.

Proteins with expanded polyQ repeats are associated with at least nine neurodegenerative disorders including ataxins 1 and 3, Kennedy's disease, and Huntington's disease (HD) $)^{1,2}$. These diseases are dominantly inherited and although the polyQ-containing proteins are expressed widely in the brain, they result in selective neuronal death. There is a significant and striking correlation between the length of the polyQ repeat and pathology; longer repeats result in earlier onset and more severe symptoms with the threshold of approximately 40 glutamine residues. In the case of $\mathrm{HD}$, for example, expanded polyQ in huntingtin (htt) protein causes disease $\mathrm{e}^{3,4}$. A characteristic of the polyQ diseases is the appearance of neuronal inclusions that are formed by aggregation of the polyQ proteins with other cellular proteins ${ }^{5,6}$. This has led to the "toxic gain-of-function” hypothesis that essential proteins can be sequestered, which 
over time leads to cellular dysgenesis. The expression of polyQ can cause other metastable proteins to lose functionality, and in turn these proteins amplify the toxicity of polyQ by enhancing overall aggregation ${ }^{7}$. Self-aggregation of polyQ proteins has been proposed to be mediated by association of parallel $\beta$-sheet structures ${ }^{8}$. However, the intrinsic in vivo events leading to the aggregation of polyQ proteins remain poorly understood.

Protein misfolding is a natural consequence of protein biogenesis. To combat cytotoxicity that results from the accumulation of misfolded proteins, all cells express molecular chaperones that are essential for the productive folding of proteins ${ }^{9,10}$. Molecular chaperones are of several classes; for example, Hsp70/J-domain proteins interact with unfolded or partially folded proteins in concert with co-chaperones, while the chaperone machines of the chaperonin (Hsp60) family form cage-like structures that sequester non-native states of proteins ${ }^{11}$. The chaperonin containing $t$-complex polypeptide 1 (CCT)/t-complex polypeptide 1 ring complex (TRiC) is a member of chaperonin family ${ }^{12}$ that facilitates the folding of proteins in the eukaryotic cytosol upon ATP hydrolysis $^{13,14}$. CCT shows a weak but significant homology to E. coli GroEL and forms a hexadecamer double-troidal complex composed of eight different subunits $^{15,16}$. Substrate proteins are captured in the cavity, and released after folding is completed ${ }^{17}$. Approximately $10 \%$ of newly-synthesized proteins have been proposed to be recognized by CCT.

Recently, in a genome-wide screen to identify modifier genes for polyQ aggregation in C. elegans, approximately 200 genes were found to be required for the prevention of polyQ aggregation ${ }^{18}$. This included the genes encoding two Hsp70s, one J-protein, and six CCT subunits. These observations suggested a 
role of CCT in preventing polyQ aggregation. We show here in mammalian cells that CCT has a key protective role against the toxicity of htt/polyQ and affects aggregation process at the soluble stage. In the context of our recent in vitro data showing that CCT prevents aggregation of the trimeric G protein $\beta$ subunit (G $\beta$ ) by recognizing hydrophobic $\beta$-strands ${ }^{19}$, we discuss possible mechanisms for the CCT-dependent prevention of polyQ aggregation.

To address whether CCT had a direct role in polyQ aggregation and toxicity, we depleted the levels of CCT in human tissue culture cells using an RNAi-mediated CCT subunit knockdown system. HEK293 cells were transiently transfected with a CCT $\zeta$ subunit siRNA expression vector or a nonspecific RNAi vector as a control, and the levels of CCT subunits were examined by western blot analysis (Fig. 1a, and see Supplementary Information, Fig. S5). The level of CCT $\zeta$ was reduced by more than $75 \%$, indicating efficient knockdown of the subunit. Except for a slight reduction of the levels of CCT $\alpha$ and CCTع subunits, no significant effect of ССТ $\zeta$ knockdown was observed on the levels of the other subunits, indicating reasonably selective knockdown of the $\zeta$ subunit. Reduction in the levels of the $\zeta$ subunit did not affect overall cell morphology or cell growth rates of transfected cells under the conditions described (data not shown). However, depletion of the $\zeta$ subunit did reduce significantly the levels of the CCT complex detected by sucrose density gradient analysis. In CCT -depleted cells the majority (82\%) of the CCT subunits were monomers or small oligomers, whereas in untreated cells essentially only the high molecular weight CCT complexes (960 kDa) were detected (Fig. 1b). The CCT complex was also disrupted by CCT $\alpha$ subunit depletion in HEK293 cells (see Supplementary Information, Fig. S1a, b), and by CCT $\zeta$ depletion in HeLa cells (see 
Supplementary Information, Fig. S2a, b). Taken together, these results indicate that human cells depleted for the CCT $\zeta$ subunit have reduced levels of the CCT complex.

To examine whether reduction of CCT affected polyQ aggregation and toxicity phenotypes, we expressed different lengths of polyQ repeats fused with YFP (YFP, Q19-YFP, and Q82-YFP) in HEK293 cells with the CCT $\zeta$ siRNA vector or nonspecific siRNA vector. Following transfection, the fraction of aggregate-containing cells was monitored by fluorescent microscopy. A low level (10.9\%) of the Q82-YFP transfected cells exhibited aggregates similar to previous observations ${ }^{20}$. Upon ССT $\zeta$ depletion there was a 2.5 -fold increase in aggregate containing cells (Fig. 1c). In contrast, no effect of CCT $\zeta$ depletion was observed in cells expressing either Q19-YFP or YFP alone. We also confirmed that the nonspecific RNAi vector exhibits no significant difference to a

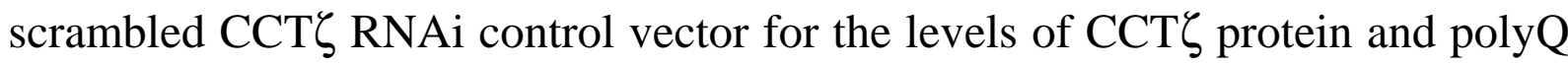
aggregation (see Supplementary Information, Fig. S1c, d). In addition, we examined whether depletion of other CCT subunits affected polyQ aggregation by RNAi knockdown and found that depletion of the CCT $\alpha$ subunit significantly stimulates Q82-GFP aggregation (Fig. 1d). These results indicate that the effect of knockdown of different subunits of CCT is an enhancement of polyQ aggregation. These observations are consistent with the fact that all eight subunits are essential to form functional chaperonin complex.

The morphological characteristics of Q82-YFP inclusions visualized in CCTל knockdown cells were indistinguishable from control Q82-YFP expressing cells in terms of the numbers of aggregate structures per cell, aggregate size, or peri-nuclear localization (Fig. 1e). Consistent with the visual 
increase in the number of cells with aggregates, cellulose acetate filter trap assay of cell lysates indicated that the cells depleted of CCT have increased levels of Q82-YFP aggregates (1.7-fold), while cells expressing either Q19-YFP or YFP alone did not form aggregates even after ССТ $\zeta$ knockdown (Fig. 1f).

We next examined whether changes in the levels of CCT influenced htt phenoytpes using HeLa cells stably expressing httQ143-YFP or httQ23-YFP under the control of Tet-off system. In httQ143-YFP cells transfected with the СCT $\zeta$ knockdown vector (transfected cells were identified by cotransfection with mRFP1 vector), the fraction of cells with aggregates increased 2.8-fold (Fig. 2a). Aggregate size and morphology was likewise unaltered (Fig. 2b) similar to what has been reported previously ${ }^{20,21}$. Consistent with the visual increase in aggregate-containing cell numbers was an increase in htt protein detected by the filter trap assay for 7.5-fold (Fig. 2c). Aggregation of httQ55 fused with HA tag consisting of only ten amino acids was also stimulated by depletion of each of two different subunits tested (Fig. 2d, and see Supplementary Information, Fig. S2c), confirming that the stimulation of htt aggregation by CCT depletion was not influenced by the heterologous presence of the YFP (GFP) tag. Thus, CCT is required to prevent the aggregation of polyQ-expansion proteins including htt.

It has been shown previously that Hsp70 inhibits polyQ aggregation in vitro and in vivo ${ }^{22,23}$. Hsp70 colocalizes to htt/polyQ aggregates and exhibits dynamic interactions in human cells unlike other associated cellular proteins that are stably sequestered ${ }^{24}$. We therefore examined the subcellular localization of CCT in htt aggregate-containing cells by immunostaining and detected the diffuse distribution of CCT throughout the cytosol but not in association with visible htt inclusions (Fig. 2e). Similar results were obtained for Q82-YFP 
inclusions (see Supplementary Information, Fig. S1e). These results are consistent with the distinct chaperone activities between CCT and Hsp70. As CCT functions as a cage for folding reactions, we postulate that CCT is diffusely distributed in the cytosol in proximity of translating ribosomes. Consistent with this notion, colocalization of CCT with soluble httQ143-YFP and ribosomes was observed in cells with no visible inclusion (Fig. 2f). Thus, CCT may affect aggregation process of htt at an earlier soluble stage.

To address how CCT influences polyQ aggregation states, we employed dynamic imaging methods. FRAP analysis did not reveal any differences in the mobility of polyQ-GFP upon depletion of CCT (see Supplementary Information, Fig. S3), therefore we turned to fluorescence correlation spectroscopy (FCS), a method developed for the analysis of rapid movement of fluorescent molecules at near single molecule levels ${ }^{25,26}$. After co-transfection of HEK293 cells with polyQ-GFP and RNAi vectors for $72 \mathrm{~h}$, cell extracts were prepared and the soluble fractions were analyzed by FCS. The record of fluorescent fluctuation indicated that significant numbers of slowly diffusing bright molecules were passing through the confocal volume in the soluble fraction prepared from cells expressing Q82-GFP or httQ143-YFP under CCT depleted conditions (Fig. 3a). The shift of correlation curves to larger diffusion times of Q82-GFP by CCTל depletion indicates that molecular sizes of the polyQ protein have become significantly larger as the levels of CCT are reduced (Fig. 3b). In contrast, Q19-GFP or GFP alone exhibited no significant difference in diffusion upon CCT depletion. Curve fitting of these data (Table 1) indicates that a fraction of Q82-GFP (F2) diffuses much more slowly than monomer fractions (F1) even in the untreated cells. The diffusion constants of these fractions indicate that the 
slow fraction diffuses 8-fold (or more) more slowly than monomers, and that the content of the slow fraction was increased by 2 -fold (8.7\% vs 4.6\%) after ССТ $\zeta$ knockdown. Likewise, we observed an increase in diffusion mobility in the soluble fraction of httQ143-YFP expressing HeLa cells whereas httQ23-YFP and YFP showed no difference (Fig. 3b). The diffusion of the slow fraction of httQ143-YFP was 30-fold slower than monomers and its relative content was increased significantly (1.2\% to $6.5 \%)$ by CCT depletion (Table 1$)$. In contrast, no difference of diffusion mobility was observed at earlier time points of 24 or $48 \mathrm{~h}$ (see Supplementary Information, Fig. S4). The slow fraction of Q82-YFP or httQ143-YFP thus appeared within the last $24 \mathrm{~h}$ of the $72 \mathrm{~h}$ RNAi treatment, corresponding to the same period when visible aggregates formed (no visible aggregates were observed at 24 and $48 \mathrm{~h}$ treatment, data not shown). Soluble aggregates of Q82-GFP were also detected in CCT depleted cells using sucrose gradient centrifugation followed by western blotting, while they were hardly detected in control cells likely due to the detection limit of the method (See Supplemental Information, Fig. S1f). Taken together, these data support the notion that inhibition of CCT function enhances the appearance of soluble htt/polyQ aggregates leading to the formation of visible inclusions.

To examine whether changes in the levels of CCT also affected htt/polyQ-induced neuronal cell death, we expressed htt in Neuro2a cells under conditions of CCT depletion. Reduction of CCT resulted in a near doubling of polyQ expansion-dependent cell death (Fig. 4a) along with a 2-fold stimulation of aggregation (Fig. 4b). We next asked whether overexpression of CCT would suppress htt/polyQ aggregation and cytotoxicity. To achieve increased expression of CCT complex, Neuro2a cells were co-transfected with expression vectors for 
all eight CCT subunits (Fig. 4e, f). This resulted in a significant inhibition of httQ78 aggregation in Neuro2a cells (Fig. 4d) and polyQ82 aggregation in HEK293 cells (see Supplementary Information, Fig. S1g). In contrast, overexpression of only a single subunit of CCT had no effect on polyQ82 aggregation (see Supplementary Information, Fig. S1h). Simultaneous overexpression of all eight CCT subunits reduced cell death of the Neuro2a expressing httQ78 by more than 50\% (Fig. 4c), thus indicating that CCT has a positive protective role against the cytotoxicity of polyQ-expansion proteins like htt.

In this study, we have shown that changes in the levels of the cytosolic chaperonin CCT affect the aggregation state and toxicity of htt/polyQ proteins in mammalian cells. RNAi knockdown of CCT subunits disrupt the CCT complex to its monomer subunits and consequently blocks the ability to trap substrates ${ }^{16,17}$. Consistent with our results, Behrends et al. have shown in yeast that CCT/TRiC prevents htt/polyQ aggregation and toxicity (Behrends, C., Langer, C.A., Bottcher, U., Stemp, M.J., Schaffar, G., Giese, A., Kretzschmar, H., Siegers, K. and Hartl F.U, personal communication). Intriguingly, our FCS experiments revealed that CCT depletion results in the appearance of soluble polymeric htt/polyQ species while CCT knockdown does not alter size or morphology of finally formed visible aggregates. Thus, CCT appears to inhibit aggregate formation at an earlier soluble stage.

Recently we demonstrated using an in vitro translation system reconstituted with purified proteins that CCT prevents aggregation of newly synthesized G $\beta^{19}$, a WD40 repeat protein very rich in $\beta$-sheets. Detailed analysis of the CCT binding regions in G $\beta$ revealed that CCT specifically recognizes 
hydrophobic $\beta$-strands. Thus, a specific function of CCT may be to protect against aggregation of hydrophobic $\beta$-sheets. Consistent with this proposal, CCT has been shown to bind hydrophobic $\beta$-strands in $\mathrm{VHL}^{27}$ and interact with the WD40 family $\beta$-sheet rich proteins in vivo ${ }^{28}$. As polyQ repeats are known to form $\beta$-sheet structures in aggregates, CCT may have an essential role to trap $\beta$-sheet structures required for aggregate formation.

HSP70 has been shown to prevent htt/polyQ aggregation in vitro ${ }^{22}$ and transiently interacts with visible aggregates in vivo ${ }^{24}$. In contrast, we show here that CCT does not concentrate in the visible htt/polyQ aggregate structure but rather remains localized throughout the cytosol. As CCT functions as a cage-like machine that assists in folding of substrates by trapping within the cavity, the structure of CCT may prevent association with large insoluble inclusions. Our data from FCS analysis supports this notion because CCT affects the formation of soluble aggregates but not of the large visible aggregates. Although we do not know the exact mechanism by which CCT affects polyQ folding, these observations suggest a biochemical process that is distinct from the mechanisms proposed for Hsp70 interaction with unfolded and partially folded substrates. Differences in the levels of the Hsp70 and CCT chaperones could therefore influence aspects of cell type sensitivity to the stress of misfolded proteins.

Overexpression of the CCT complex has a significant inhibitory effect on the aggregation and cytotoxicity of htt/polyQ in mammalian cells. Therefore, modulation of CCT function may offer an approach to prevent neurodegenerative disorders caused by protein aggregation including polyQ diseases. 


\section{METHODS}

Constructs. Plasmid vectors expressing siRNAs for 21-nucleotide target sequences of human СCT $\zeta-1$ mRNA (AAGTCTGTGGCGATTCAGATA), human CCT $\alpha$ mRNA (AAATACTAAGGCTCGTACGTC) and mouse CCT $\zeta-1$ mRNA (AAGTCTGTGGTGACTCAGATA) were constructed using pSUPER (OligoEngine). A non-silencing control vector expressing non-specific siRNA (NS-pSUPER) was obtained from Darmacon. Expression vectors of polyQ-EYFP and polyQ-EGFP were described previously ${ }^{20,24}$. Expression vectors of htt exon-1 fused with EYFP were produced as described previously ${ }^{21}$, and the htt exon-1 gene inserts were then subcloned into pEGFP-N1 (Invitrogen) for htt-EGFP expression vectors. mRFP1 expression vector was constructed by excising the mRFP1 insert form mRFP1/pRsetB ${ }^{29}$ and subcloned into pEGFP-C1 vector after removing the EGFP segment. For overexpression of eight CCT subunits, human cDNAs of individual subunits were separately cloned into pCAGGS expression vector.

Cell culture, transfection and biochemical analysis. HEK293, HeLa and Neuro2a cells were cultured in Dulbecco's modified Eagle's medium supplemented with $10 \%$ fetal bovine serum. HeLa stable cell lines carrying Tet-off-regulated htt-EYFP genes were cloned and maintained as described previously $^{21}$. HEK293, HeLa and Neuro2a cells were transfeceted using Lipofectamine 2000, Optifect (Invitrogen), and Effectene (Qiagen), respectively. For the HeLa stable cell lines, they were co-transfected with mRFP1 and other plasmids, and cells emitting red color signals of mRFP1 were determined as 
transfected cells. Determination of protein concentration, western blotting analysis and sucrose gradient fractionation were performed as described previously $^{30}$. For CCT overexpression experiments, Neuro2a cells (3.5 cm dish) were transfected with the eight CCT subunit expression vectors (10 ng each), htt-GFP (100 ng) and empty pCAGGS (320 ng). For control experiments, the CCT subunit expression vectors were replaced by the same amount of empty pCAGGS.

Analysis of aggregate-containing cells. Cells were grown on coverslips coated with poly-L-Lysine for HEK293 cells, type I collagen for HeLa cells, or type IV collagen for Neuro2A cells, respectively. At $72 \mathrm{~h}$ after transfection, cells were fixed with 4\% paraformaldehyde in PBS for 15 min, and stained with Hoechst 33342. Images were taken by an Axioplan2 microscope with Plan-NeoFluar 40x/0.75 NA objective (Carl Zeiss).

Analysis of cell death. Neuro2a cells were grown on $\phi 27$ glass-bottom dish coated with type IV collagen for $16 \mathrm{~h}$. Immediately after transfection of htt-GFP expression vectors, neuronal cell differentiation was induced by addition of 5 mM Dibutyryl cAMP for $72 \mathrm{~h}$. Cells stained with propidium iodide $(1 \mu \mathrm{g} / \mathrm{ml})$ were counted as dead cells using a Biozero digital microscope (Keyence) through a PlanFluor 10x/0.30 NA objective (Nikon).

Filter trap assay. Cells were lysed in PBS containing 0.5\% TritonX-100, and protein concentration were determined. Lysates were diluted in 1\% SDS/PBS and boiled for 5 min. Immediately after cooling, samples were loaded onto 
cellulose acetate membrane $(0.2 \mu \mathrm{m})$ settled on a dot blotter (Bio-Rad). After blocking with $1 \%$ skim milk and $0.05 \%$ Tween 20 in PBS overnight, membrane was incubated with mouse anti-GFP antibody (GA200, Nacalai Tesque) and alkaline-phosphatase conjugated anti-mouse IgG antibody (Biosource). Alkaline-phosphatase activity was detected by developing in NBT/BCIP solution (Sigma-Aldirich).

Immunofluorescence. Cells grown on coverslips were fixed in methanol at $-20^{\circ} \mathrm{C}$ for $5 \mathrm{~min}$ or $4 \%$ paraformaldehyde in PBS at $37^{\circ} \mathrm{C}$ for $15 \mathrm{~min}$ and washed three times in PBS. After treatment with 0.5\% Triton X-100 and 0.5\% Saponin in PBS for 5 min, cells were blocked with 1\% BSA, 10\% Glycerol and 0.02\% Triton X100 in PBS. Cells were incubated with rabbit anti-CCT $\gamma$ antibody (1/50), rat anti-HSC70 antibody (1/100, SPA-815, Stressgen), mouse anti- $\alpha$-tubulin antibody (1/200, DM1A, CalbioChem), mouse anti-GFP antibody (1/100), or goat anti-Ribosomal protein L11 (1/50, sc-25931, SantaCruz) and then with AlexaFluor 488 or 594 conjugated anti-rabbit, rat, goat, or mouse IgG (1/200, Molecular Probes). At the second antibody incubation, cells were costained with $1.0 \mu \mathrm{g} / \mathrm{ml}$ Hoechst 33342 for nuclear staining. Images were collected by LSM 510 META confocal microscope through a Plan-Apochromat 63x/1.4 NA oil-immersion objective (Carl Zeiss). The pinhole aparture for Hoechst, YFP, and Alexa594 channels were settled at $84 \mu \mathrm{m}, 94 \mu \mathrm{m}$, and $127 \mu \mathrm{m}$, respectively.

FCS analysis. FCS measurements were performed by a ConfoCor 2 system with C-Apochromat 40x/1.2NA water immersion objective lens (Carl Zeiss). EGFP and EYFP were excited at $488 \mathrm{~nm}$ and $514 \mathrm{~nm}$, respectively. Confocal pinhole 
diameters were adjusted to $70 \mu \mathrm{m}$ at $488 \mathrm{~nm}$, or $74 \mu \mathrm{m}$ at $514 \mathrm{~nm}$. Emission signals were detected by a $505 \mathrm{~nm}$ long-pass filter for EGFP, or a 530-600 nm band-pass filter for EYFP. Cells (3.5 cm dish) were lysed $0.2 \mathrm{ml}$ in PBS by passing through a 27G needle, and supernatant was recovered after centrifugation (10,000xg, $2 \mathrm{mim})$ and diluted appropriate. Fluorescence signals of the supernatant were recorded on Lab-Tek 8-well chamber slides at $25^{\circ} \mathrm{C}$. The fluorescence autocorrelation functions, $\mathrm{G}(\tau)$, from which the average residence time $\left(\tau_{\mathrm{i}}\right)$ and the absolute number of fluorescent proteins in the detection volume are calculated, are obtained as follows;

$$
G(\tau)=\frac{\langle I(t) I(t+\tau)\rangle}{\langle I(t)\rangle^{2}}
$$

where $I(t+\tau)$ is the fluorescence intensity obtained by the single photon counting method in a detection volume at a delay time $\tau$ (brackets denote ensemble averages). The curve fitting for the multi-component model is given by:

$$
G(\tau)=1+\frac{1}{N} \sum_{i} y_{i}\left(1+\frac{\tau}{\tau_{i}}\right)^{-1}\left(1+\frac{\tau}{s^{2} \tau_{i}}\right)^{-1 / 2}
$$

where $y_{i}$ and $\tau_{i}$ are the fraction and the diffusion time of the component $i$, respectively, $N$ is the average number of fluorescent molecules in the detection volume defined by the beam waist $w_{0}$ and the axial radius $z_{0}, s$ is the structure parameter representing the ratio of $w_{0}$ and $z_{0}$. All G( $\left.\tau\right)$ s in aqueous solutions were measured ten times for 20 s. After pinhole adjustment, diffusion time and structure parameter were determined using a $10^{-7} \mathrm{M}$ rhodamine 6G (Rh6G) solution as a standard prior to measurements. The values of structural parameter were 6.1-6.6 for GFP and 5.5-6.6 for YFP, respectively. The diffusion constants 
of fluorescent molecules ( $\left.D_{\text {sample }}\right)$ were calculated from the published diffusion constant of Rh6G, $D_{\text {Rh6G }}\left(280 \mu \mathrm{m}^{2} / \mathrm{s}\right)$ and measured diffusion times of Rh6G at the condition ( $\left.\tau_{\mathrm{Rh} 6 \mathrm{G}}\right)$ and probe proteins $\left(\tau_{\text {sample }}\right)$ as follows:

$$
\frac{D_{\text {sample }}}{D_{\text {Rh6G }}}=\frac{\tau_{\text {Rh } 6 G}}{\tau_{\text {sample }}}
$$

\section{ACKNOWLEDGEMENTS}

We thank M. Kadota for technical assistance and R. Tsien for providing the mRFP1 plasmid. We are grateful to I. Wada, T. Haraguchi, H. Taguchi, Y. Nagai, T. Shimi, K. Kabayama, K. Saito and H. Fujii for helpful discussion. G.M. was supported by a Human Frontiers Fellowship at Northwestern University and R.I.M. is supported by grants from the NIH (NIGMS, NINDS, and NIA), the Huntington Disease Coalition for the Cure, and the Daniel F. and Ada L. Rice Foundation.

1. Ross, C. A. Polyglutamine pathogenesis: emergence of unifying mechanisms for Huntington's disease and related disorders. Neuron 35, 819-822 (2002).

2. Gatchel, J. R. \& Zoghbi, H. Y. Diseases of unstable repeat expansion: mechanisms and common principles. Nat. Rev. Genet. 6, 743-755 (2005).

3. The Huntington's Disease Collaborative Research Group, A novel gene containing a trinucleotide repeat that is expanded and unstable on Huntington's disease chromosomes. Cell 72, 971-983 (1993). 
4. DiFiglia, M. et al. Huntingtin is a cytoplasmic protein associated with vesicles in human and rat brain neurons. Neuron 14, 1075-1081 (1995).

5. Davies, S. W. et al. Formation of neuronal intranuclear inclusions underlies the neurological dysfunction in mice transgenic for the HD mutation. Cell 90, 537-548 (1997).

6. Scherzinger, E. et al. Huntingtin-encoded polyglutamine expansions form amyloid-like protein aggregates in vitro and in vivo. Cell 90, 549-58 (1997).

7. Gidalevitz, T., Ben-Zvi, A., Ho, K. H., Brignull, H. R. \& Morimoto, R. I. Progressive disruption of cellular protein folding in models of polyglutamine diseases. Science 311, 1471-1474 (2006).

8. Perutz, M.F., Finch, J.T., Berriman, J. \& Lesk, A. Amyloid fibers are water-filled nanotubes. Proc. Natl. Acad. Sci. USA 99, 5591-5595 (2002).

9. Young, J. C., Agashe, V. R., Siegers, K. \& Hartl, F. U. Pathways of chaperone-mediated protein folding in the cytosol. Nat. Rev. Mol. Cell Biol. 5, 781-791 (2004).

10. Muchowski, P. J. \& Wacker, J. L. Modulation of neurodegeneration by molecular chaperones. Nat. Rev. Neurosci. 6, 11-22 (2005).

11. Fenton, W. A. \& Horwich, A. L. Chaperonin-mediated protein folding: fate of substrate polypeptide. Q. Rev. Biophys. 36, 229-256 (2003).

12. Spiess, C., Meyer, A. S., Reissmann, S. \& Frydman, J. Mechanism of the eukaryotic chaperonin: protein folding in the chamber of secrets. Trends Cell Biol. 14, 598-604 (2004).

13. Frydman, J. \& Hartl, F. U. Principles of chaperone-assisted protein folding: differences between in vitro and in vivo mechanisms. Science 272, 
1497-1502 (1996).

14. Farr, G. W., Scharl, E. C., Schumacher, R. J., Sondek, S. \& Horwich, A. L. Chaperonin-mediated folding in the eukaryotic cytosol proceeds through rounds of release of native and nonnative forms. Cell 89, 927-937 (1997).

15. Kubota, H., Hynes, G., Carne, A., Ashworth, A. \& Willison, K. Identification of six Tcp-1-related genes encoding divergent subunits of the TCP-1-containing chaperonin. Curr. Biol. 4, 89-99 (1994).

16. Llorca, O. et al. Eukaryotic chaperonin CCT stabilizes actin and tubulin folding intermediates in open quasi-native conformations. EMBO J. 19, 5971-5979 (2000).

17. Meyer, A. S. et al. Closing the folding chamber of the eukaryotic chaperonin requires the transition state of ATP hydrolysis. Cell 113, 369-381 (2003).

18. Nollen, E. A. et al. Genome-wide RNA interference screen identifies previously undescribed regulators of polyglutamine aggregation. Proc. Natl. Acad. Sci. USA 101, 6403-6408 (2004).

19. Kubota, S., Kubota, H. \& Nagata, K. Cytosolic chaperonin protects folding intermediates of G $\beta$ by recognizing hydrophobic $\beta$-strands. Proc. Natl. Acad. Sci. USA 103, 8360-8365 (2006).

20. Holmberg, C. I., Staniszewski, K. E., Mensah, K. N., Matouschek, A. \& Morimoto, R. I. Inefficient degradation of truncated polyglutamine proteins by the proteasome. EMBO J. 23, 4307-4318 (2004).

21. Matsumoto, G., Kim, S. \& Morimoto, R. I. Huntingtin and mutant SOD1 form aggregate structures with distinct molecular properties in human cells. J. Biol. Chem. 281, 4477-4485 (2005). 
22. Muchowski, P. J. et al. Hsp70 and hsp40 chaperones can inhibit self-assembly of polyglutamine proteins into amyloid-like fibrils. Proc. Natl. Acad. Sci. USA 97, 7841-7846 (2000).

23. Schaffar, G. et al. Cellular toxicity of polyglutamine expansion proteins: mechanism of transcription factor deactivation. Mol. Cell 15, 95-105 (2004).

24. Kim, S., Nollen, E. A., Kitagawa, K., Bindokas, V. P. \& Morimoto, R. I. Polyglutamine protein aggregates are dynamic. Nat. Cell. Biol. 4, 826-831 (2002).

25. Rigler, R., Mets, U., Widengren, J. \& Kask, P. Fluorescence correlation spectroscopy with high count rate and low background: analysis of translational diffusion. Eur. Biophys. J. 22, 169-175 (1993).

26. Terada, S., Kinjo, M. \& Hirokawa, N. Oligomeric tubulin in large transporting complex is transported via kinesin in squid giant axons. Cell 103, 141-155 (2000).

27. Feldman, D. E., Spiess, C., Howard, D. E. \& Frydman, J. Tumorigenic mutations in VHL disrupt folding in vivo by interfering with chaperonin binding. Mol. Cell 12, 1213-1224 (2003).

28. Siegers, K. et al. TRiC/CCT cooperates with different upstream chaperones in the folding of distinct protein classes. EMBO J. 22, 5230-5240 (2003).

29. Campbell, R. E. et al. A monomeric red fluorescent protein. Proc. Natl. Acad. Sci. USA 99, 7877-7882 (2002).

30. Yokota, S., Yanagi, H., Yura, T. \& Kubota, H. Cytosolic chaperonin is up-regulated during cell growth. Preferential expression and binding to 
tubulin at G(1)/S transition through early S phase. J. Biol. Chem. 274, 37070-37078 (1999). 
Figure legends

Figure 1 CCT knockdown stimulates aggregate formation of expanded polyQ repeats transiently expressed in HEK293 cells. (a) Knockdown of the $\zeta$ subunit of CCT. Cells were transiently transfected with CCTל RNAi vector, or nonspecific RNAi vector (NS) as a control. Cellular proteins were extracted after $72 \mathrm{~h}$ and analyzed by western blotting using antibodies against individual subunits. (b) CCT complex is disrupted by CCT $\zeta$ knockdown. Proteins extracted from CCT $\zeta$ RNAi-treated cells, or untreated cells, were fractionated by sucrose gradient centrifugation. Fractions were analyzed by western blotting using

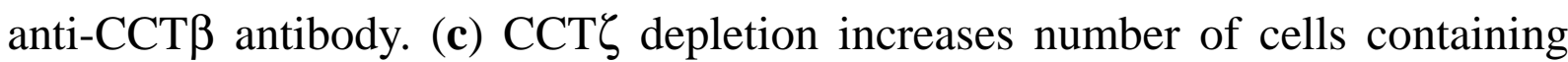
Q82-YFP aggregates. Cells were transfected with polyQ expression vector (Q82-YFP, Q19-YFP or YFP alone) in the presence of CCT $\mathrm{RNAi}$ or non-specific RNAi vectors. Number of cells showing YFP fluorescence with or without aggregates were counted, and the percentage of aggregate positive cells were calculated $(n=3)$. (d) Q82-GFP aggregation is stimulated by RNAi knockdown of CCT $\alpha$. (e) Fluorescent microscopic images of polyQ-YFP expressed in HEK293 cells treated with CCT $\zeta$ RNAi or non-specific RNAi vectors. Bar=20 $\mu \mathrm{m}$. (f) Filter trap assay of polyQ-YFP aggregates. Cell lysates containing indicated amount of protein were filtered on cellulose acetate membranes, and polyQ-YFP aggregates were detected by immunoblotting using anti-YFP antibody. **, $P<0.01$; Student's $t$ test.

Figure 2 CCT is required for preventing htt aggregation in stable transformants of HeLa cells. (a) CCT $\zeta$ depletion increases number of cells containing 
httQ143-YFP aggregates. Cells were co-transfected with vectors for CCT $\zeta$ RNAi and mRFP1 expression as a transfection marker, and Htt-YFP expression was simultaneously induced by removal of tetracycline from the medium. Cells containing YFP-aggregates were counted and their percentage in RFP-signal emitting cells were determined. (b) Fluorescent images of aggregated httQ143-YFP and diffusely distributed httQ23-YFP in CCT $\zeta$-depleted and control cells. Arrows indicate aggregates. Bar=20 $\mu \mathrm{m}$. (c) Filter trap assay of htt-YFP aggregates in CCT-depleted and control cells. (d) Aggregation of httQ55-HA is stimulated by depletion of CCT $\alpha$ or CCT $\zeta$. Cells were cotransfected with expression vectors of httQ55-HA and CCT subunit RNAi vectors, and stained with anti-HA antibody after fixation. Percentages of aggregate positive cells are shown. (e) Cells with visible httQ143 inclusions were stained with antibodies against CCT $\gamma$, HSC70 or $\alpha$-tubulin and AlexaFluor 594-conjugated secondary antibody. Insets correspond to enlarged view of aggregates. (f) Cells with no visible inclusion were stained using antibodies against GFP (for httQ143-YFP), CCT $\gamma$, and ribosome. Bar=10 $\mu \mathrm{m}$. **, $P<0.01$.

Figure 3 CCT depletion stimulates formation of soluble aggregates of polyQ-expansion proteins detected by FCS analysis. (a) GFP, Q19-GFP or Q82-GFP were transiently expressed in HEK293 cells in the presence of CCTל RNAi vector or nonspecific RNAi vector. Alternatively, expression of YFP, httQ23-YFP or httQ143-YFP were induced in HeLa stable cell lines in the presence of CCT $\zeta$ RNAi or nonspecific RNAi vectors. After $72 \mathrm{~h}$ of expression, cells were lysed in PBS. Supernatant recovered after centrifugation (10,000xg) was analyzed by FCS. (a) Count rates of fluorescence in $\mathrm{CCT} \zeta$-depleted (red) 
and control (blue) cell lysates during $20 \mathrm{~s}$ measurements. Arrows indicate slowly diffusing bright molecules that were passing through the confocal volume. (b) Correlation curves of htt/polyQ proteins in $\mathrm{CCT} \zeta$-depleted (red) and control (blue) cell lysates.

Figure 4 CCT prevents htt toxicity and aggregation in neuronal cells. (a) CCT depletion enhances htt-induced neuronal cell death. Mouse Neuro2a cells were transfected with htt-GFP expression vector along with CCT $\zeta$ RNAi or nonspecific RNAi vectors. Cells were stained by propidium iodide to monitor cell death and percentage in GFP expressing cells were calculated $(n=3)$. (b) CCT depletion enhances htt aggregation in Neuro2a cells $(n=3)$. (c) CCT overexpression reduces htt-induced neuronal cell death. Neuro2a cells were co-transfected with expression vectors of htt-GFP and all eight CCT subunits. (d) CCT overexpression reduces htt aggregation in Neuro2a cells $(n=3)$. (e) Neuro2a cells were transfected with expression vectors of all eight CCT subunits, and total proteins extracted were analyzed by western blotting. (f) The extracts described in panel e were fractionated by sucrose gradient centrifugation and subsequently analyzed by western blotting using anti-CCT $\beta$ antibody. *, $P<0.05$; **, $P<0.01$. 
Table 1 Diffusion constants of htt/polyQ proteins under CCT-depleted and normal conditions

\begin{tabular}{|c|c|c|c|c|c|c|c|c|}
\hline & \multirow[b]{2}{*}{ RNAi } & \multicolumn{2}{|c|}{ Rapid fraction (F1) } & \multicolumn{2}{|c|}{ Slow fraction (F2) } & \multirow[b]{2}{*}{$\chi^{2}$} & \multirow[b]{2}{*}{$D_{\mathrm{F} 1}\left(\mu \mathrm{m}^{2} / \mathrm{s}\right)$} & \multirow[b]{2}{*}{$D_{\mathrm{F} 2}\left(\mu \mathrm{m}^{2} / \mathrm{s}\right)$} \\
\hline & & DT $(\mu \mathrm{s})$ & Content (\%) & DT $(\mu \mathrm{s})$ & Content (\%) & & & \\
\hline GFP & NS & $70.7 \pm 1.5$ & 100 & - & - & $1.19 \pm 1.76 \times 10^{-6}$ & $85.8 \pm 0.8$ & - \\
\hline GFP & ССТ丂 & $70.7 \pm 2.1$ & 100 & - & - & $1.67 \pm 2.61 \times 10^{-6}$ & $85.9 \pm 1.9$ & - \\
\hline Q19-GFP & NS & $86.3 \pm 4.0$ & 100 & - & - & $7.43 \pm 11.33 \times 10^{-7}$ & $70.3 \pm 2.8$ & - \\
\hline Q19-GFP & ССТ & $86.0 \pm 3.6$ & 100 & - & - & $5.24 \pm 8.45 \times 10^{-7}$ & $70.6 \pm 2.0$ & - \\
\hline Q82-GFP & NS & $86.0^{*}$ & $95.4 \pm 0.9$ & $1122 \pm 416$ & $4.6 \pm 0.9$ & $7.56 \pm 2.10 \times 10^{-7}$ & $71.6 \pm 1.9^{\star \star}$ & $8.3 \pm 3.7$ \\
\hline Q82-GFP & ССТל & $86.0^{*}$ & $91.3 \pm 2.4$ & $4255 \pm 1920$ & $8.7 \pm 2.4$ & $1.84 \pm 0.12 \times 10^{-6}$ & $71.6 \pm 1.9^{\star \star}$ & $3.0 \pm 1.8$ \\
\hline YFP & NS & $77.7 \pm 3.1$ & 100 & - & - & $3.22 \pm 0.24 \times 10^{-6}$ & $84.2 \pm 1.5$ & - \\
\hline YFP & 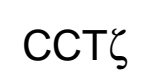 & $78.3 \pm 3.5$ & 100 & - & - & $5.13 \pm 3.37 \times 10^{-6}$ & $83.5 \pm 2.1$ & - \\
\hline httQ23-YFP & NS & $147.3 \pm 1.5$ & 100 & - & - & $6.76 \pm 3.53 \times 10^{-6}$ & $44.3 \pm 1.3$ & - \\
\hline httQ23-YFP & ССТ & $147.7 \pm 3.1$ & 100 & - & - & $6.61 \pm 1.83 \times 10^{-6}$ & $44.3 \pm 1.5$ & - \\
\hline httQ143-YFP & NS & $150.0^{*}$ & $98.8 \pm 0.4$ & $4859 \pm 1897$ & $1.2 \pm 0.4$ & $1.71 \pm 2.55 \times 10^{-5}$ & $43.6 \pm 1.1^{\star *}$ & $1.5 \pm 0.7$ \\
\hline HttQ143-YFP & ССТל & $150.0^{*}$ & $93.5 \pm 1.5$ & $5493 \pm 2540$ & $6.5 \pm 1.5$ & $3.73 \pm 2.16 \times 10^{-6}$ & $43.6 \pm 1.1^{\star *}$ & $1.3 \pm 0.5$ \\
\hline
\end{tabular}

Diffusion time (DT) and constant $(D)$ were estimated by curve fitting of the polyQ-GFP or htt-YFP FCS data at $72 \mathrm{~h}$ (mean \pm SD of three independent experiments). The deviations of diffusion constant were derived from difference between measured samples and variance of the diffusion time of Rh6G used as a standard (see Methods). The data of GFP, Q19-GFP, YFP and httQ23-YFP were analyzed by one component model while the Q82-GFP and httQ143-YFP data were analyzed by two component model to provide the best fit. Significance of curve fitting was analyzed by $\chi^{2}$ test.

* To accurately estimate the diffusion time and content of the second component (soluble aggregates) at $72 \mathrm{~h}$, the diffusion time of the first component was fixed to the values of monomers that were determined at $24 \mathrm{~h}$.

** The variance of $D$ values was provided from variance of the diffusion time of Rh6G used as a standard while the diffusion time of the first component was fixed. 
RNAi: NS CCTS

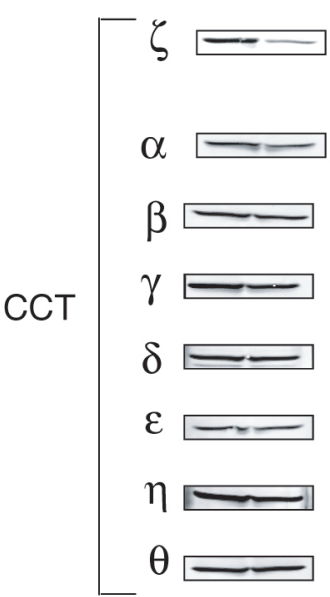

GAPDH
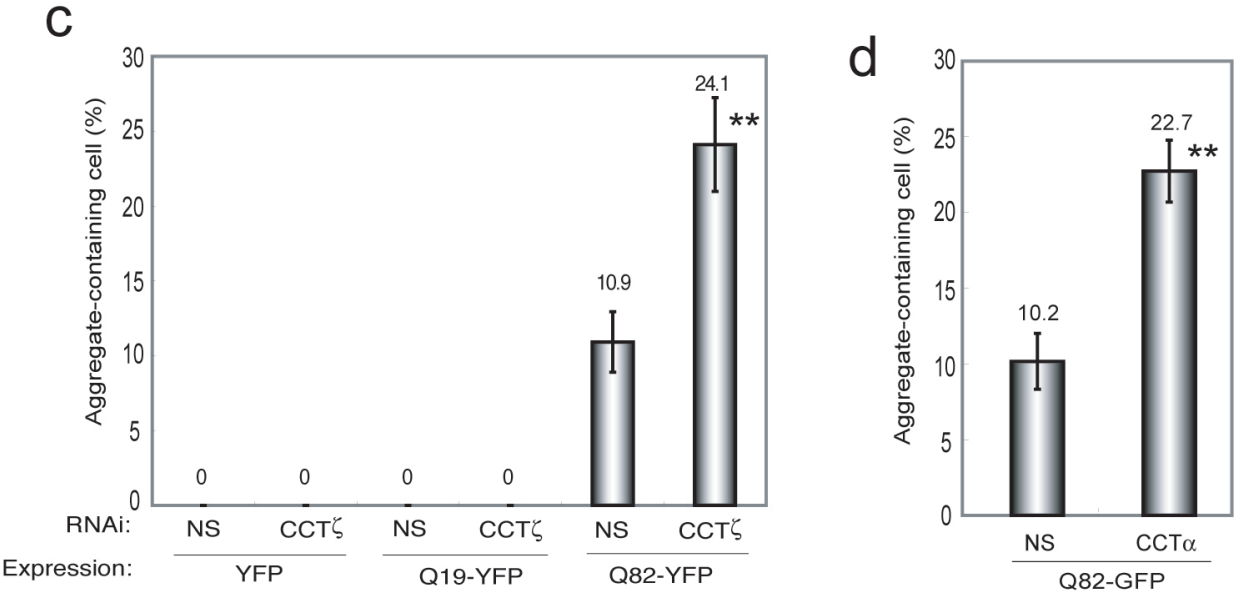

e
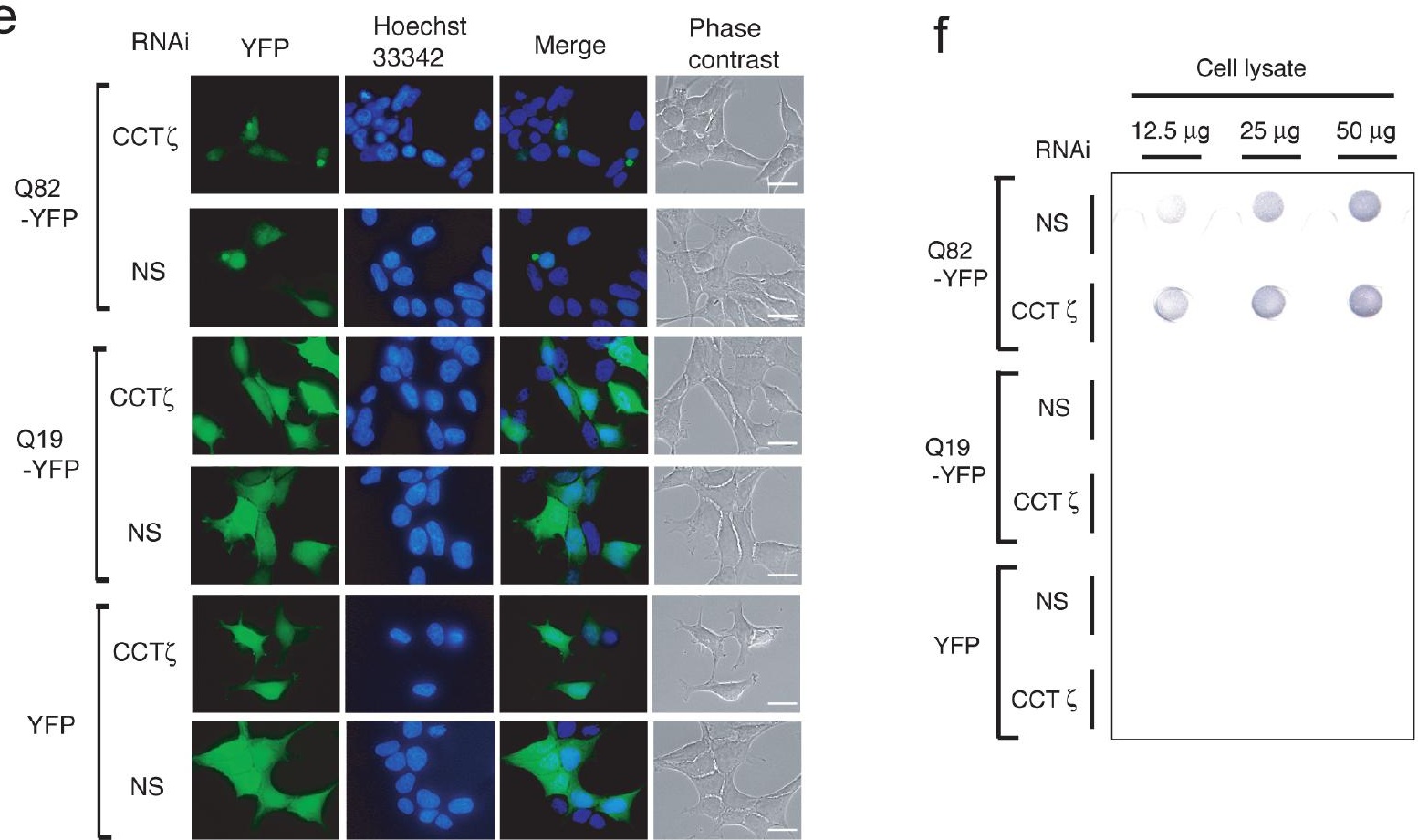
a

\section{GFP}

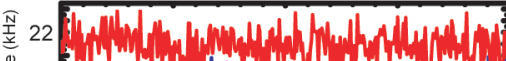

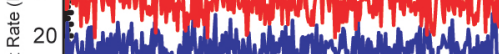

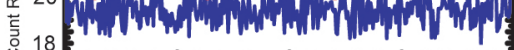

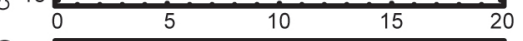

Q19GFP

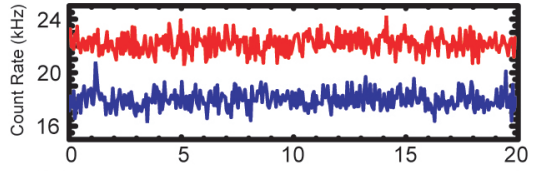

Q82-

GFP

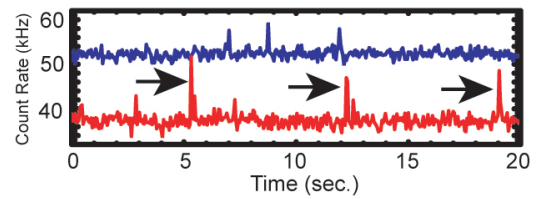

YFP
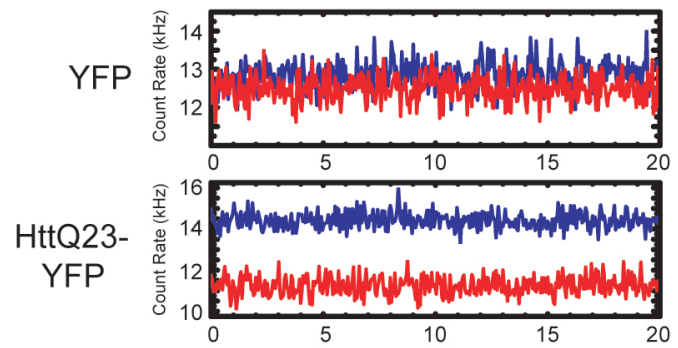

HttQ143
YFP

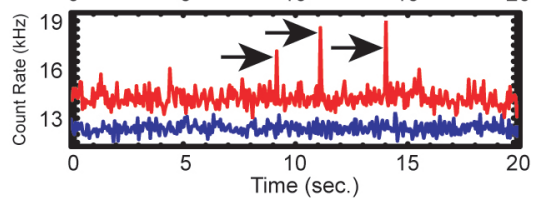

YFP

b
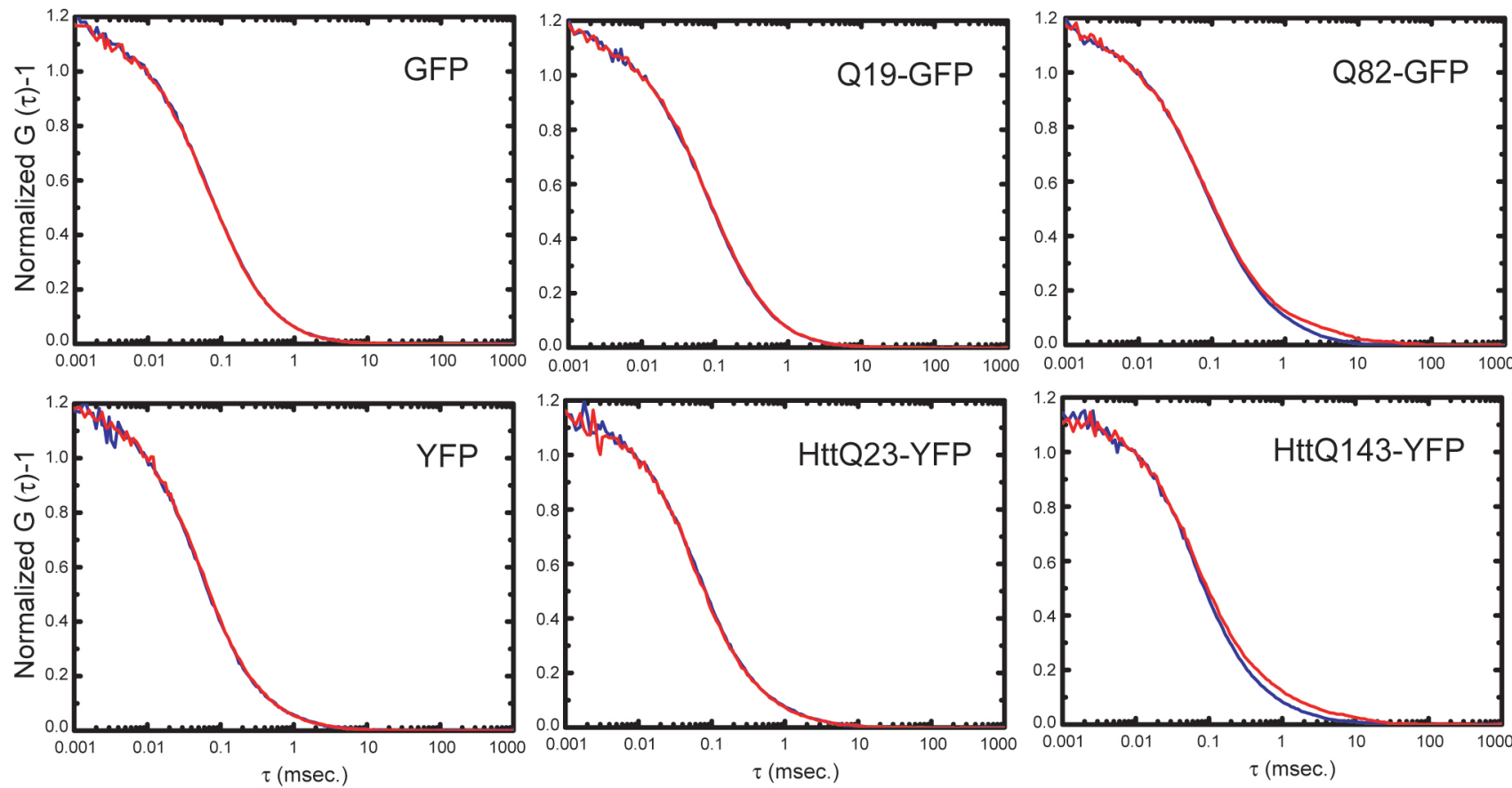


\section{a}

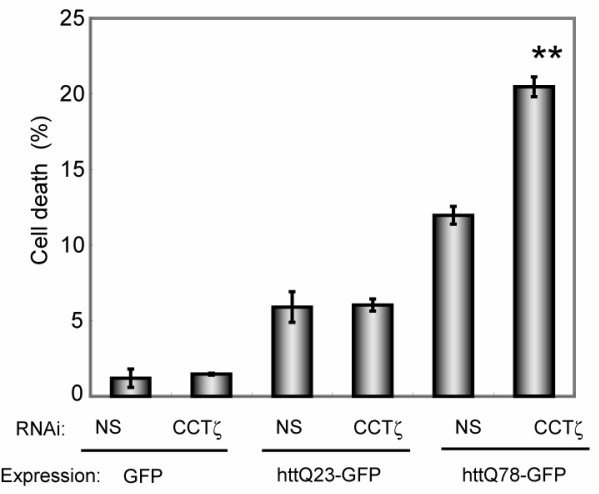

b

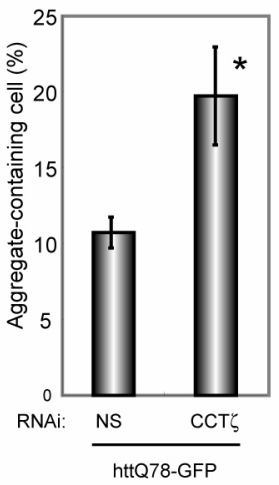

C

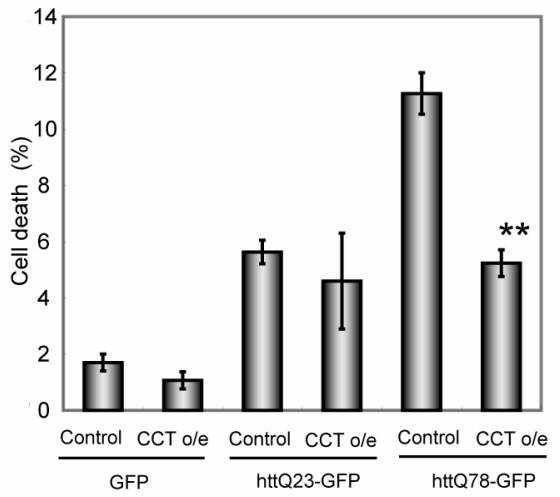

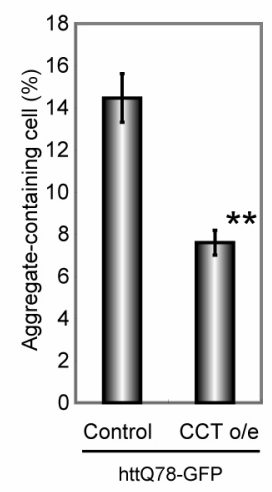

e

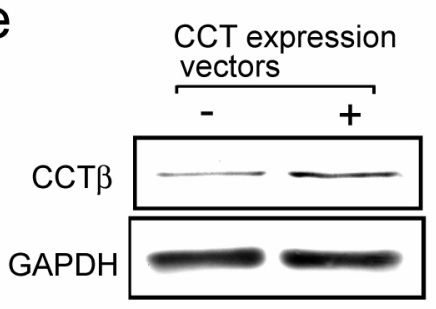

f

CCT

expression vectors

$\frac{10 \% \text { Sucrose }}{1234}$

56

WB:
$\operatorname{cct} \beta$$[+$ 


\section{Supplementary Information}

Figure S1 PolyQ aggregation in HEK293 cells under CCT depletion and overexpression conditions. Cells were transfected with CCT $\alpha$ RNAi or nonspecific RNAi vectors and analyzed by western blotting (a) or sucrose gradient centrifugation (b). Nonspecific RNAi (NS) vector exhibits no difference to $\mathrm{CCT} \zeta$ scrambled RNAi (CCT $\zeta-S C$, AAGAGTCGGCTGAGTATCATT) vector for levels of CCT $\zeta$ protein (c) and polyQ aggregation $(n=3)(\mathbf{d})$. (e) Immunofluorescent staining of CCT $\gamma$, HSC70 and $\alpha$-tubulin in Q82-YFP aggregate containing cells without RNAi treatment. Bar=10 $\mu \mathrm{m}$. (f) Sucrose gradient fractionation of Q82-GFP expressed under CCT $\zeta$ depleted or normal conditions. Supernatant after centrifugation (600xg, 2 min) was analyzed. Overexpression of all CCT subunits (g), but not of CCT $\zeta$ subunit alone (h), inhibits Q82-GFP aggregation (n=3). *, $P<0.05$.

Figure S2 Aggregation of httQ55-HA in HeLa cells under CCT depleted and normal conditions. (a) $\mathrm{CCT} \zeta$-RNAi treatment significantly reduces $\mathrm{CCT} \zeta$ protein. (b) Cell extracts were analyzed by sucrose gradient centrifugation. (c) Immunofluorescent staining of httQ55-HA aggregates formed under CCT depletion conditions. Bar=10 $\mu \mathrm{m}$.

Figure S3 FRAP analysis of polyQ-GFP in HEK293 cells under CCT-depleted conditions at $72 \mathrm{~h}$. Inclusion-free cells (a) or inclusion-containing cells (b) were analyzed by FRAP $^{1-3}$ using Olympus FV1000 (for cytosol) or Carl Zeiss LSM 510 META (for inclusions) confocal microscopes at $37^{\circ} \mathrm{C}$. CCT $\zeta$-depleted 
(green) and control (red) cells were analyzed.

1. Phair, R.D. \& Misteli, T. High mobility of proteins in the mammalian cell nucleus. Nature 404, 604-609 (2000).

2. Lippincott-Schwartz, J., Snapp, E. \& Kenworthy, A. Studying protein dynamics in living cells. Nat Rev Mol Cell Biol 2, 444-456 (2001).

3. Kimura, H. \& Cook, P.R. Kinetics of core histones in living human cells: little exchange of $\mathrm{H} 3$ and $\mathrm{H} 4$ and some rapid exchange of H2B. J Cell Biol 153, 1341-153 (2001).

Figure S4 FCS analysis of htt/polyQ proteins under CCT-knockdown conditions at 24 and $48 \mathrm{~h}$. Supernatant after centrifugation (600xg, $2 \mathrm{~min}$ ) of cell lysate was analyzed. Correlation curves of CCT $\zeta$-depleted (red) and control (blue) cells are shown for polyQ-GFP in HEK293 cells after $24 \mathrm{~h}$ (a) $48 \mathrm{~h}$ (b) of transfection, or htt-YFP in HeLa cell lines after 24 h (c) or 48 h (d) of induction.

Figure S5 Full scan images of gel/western data. 


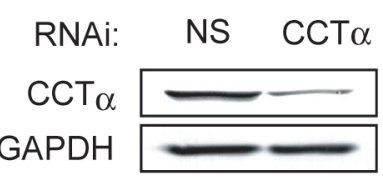

b

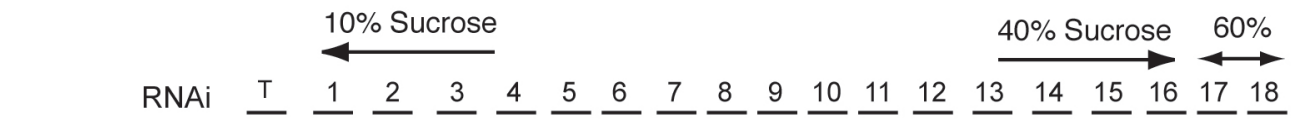

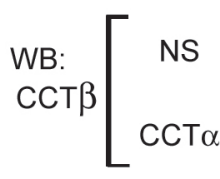

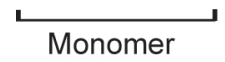

d

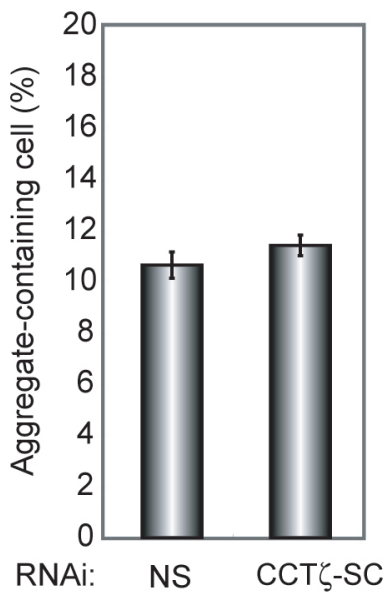

e
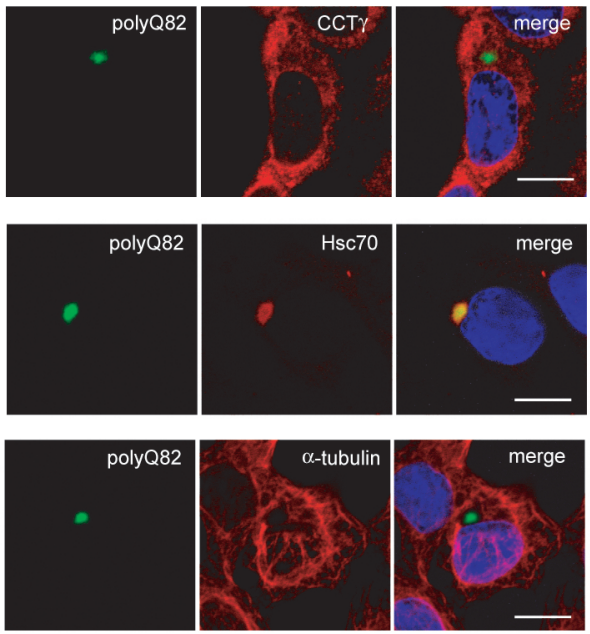

merge

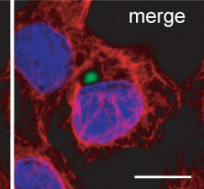

Soluble aggregate

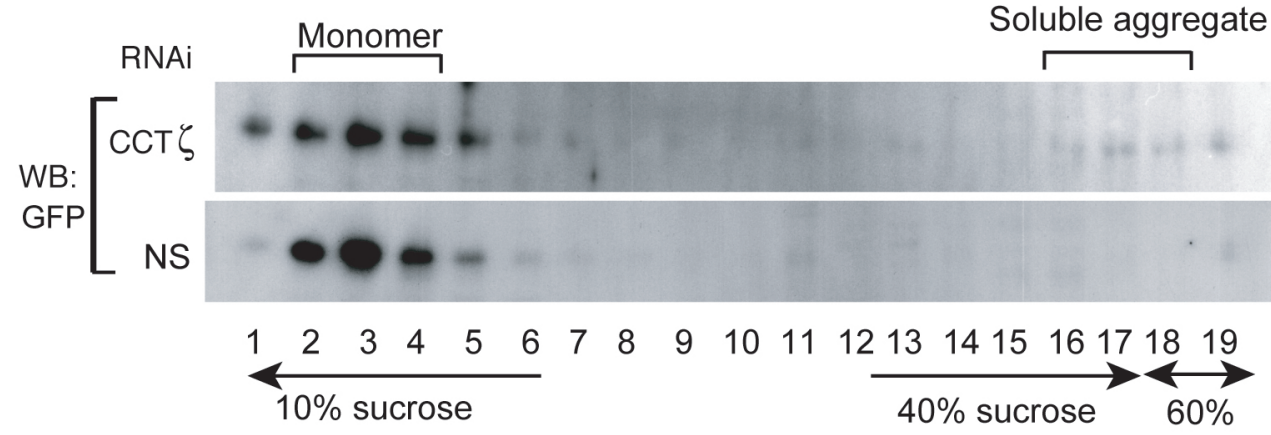

g

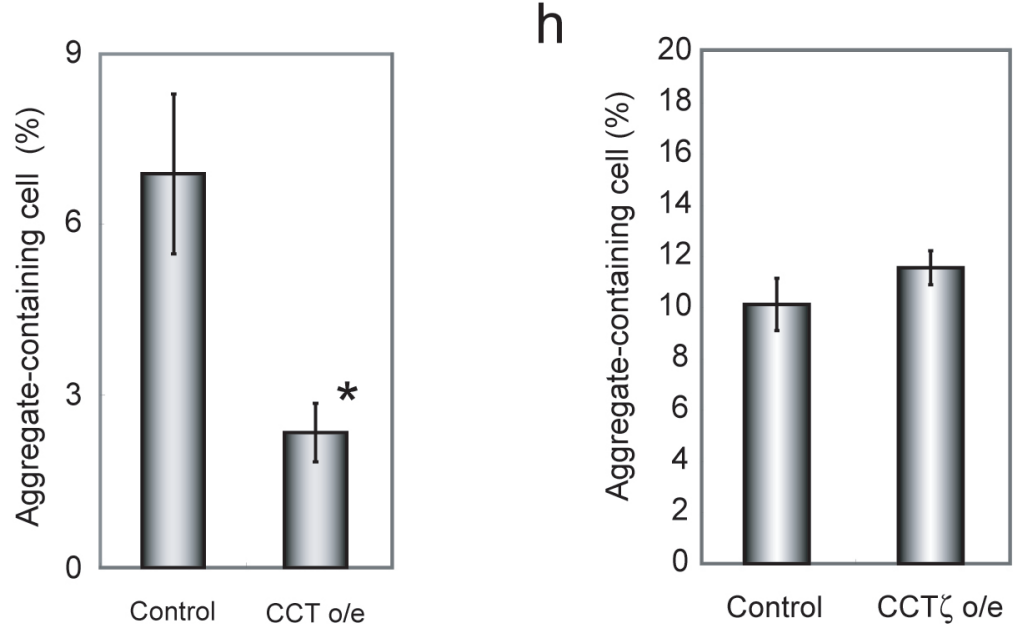




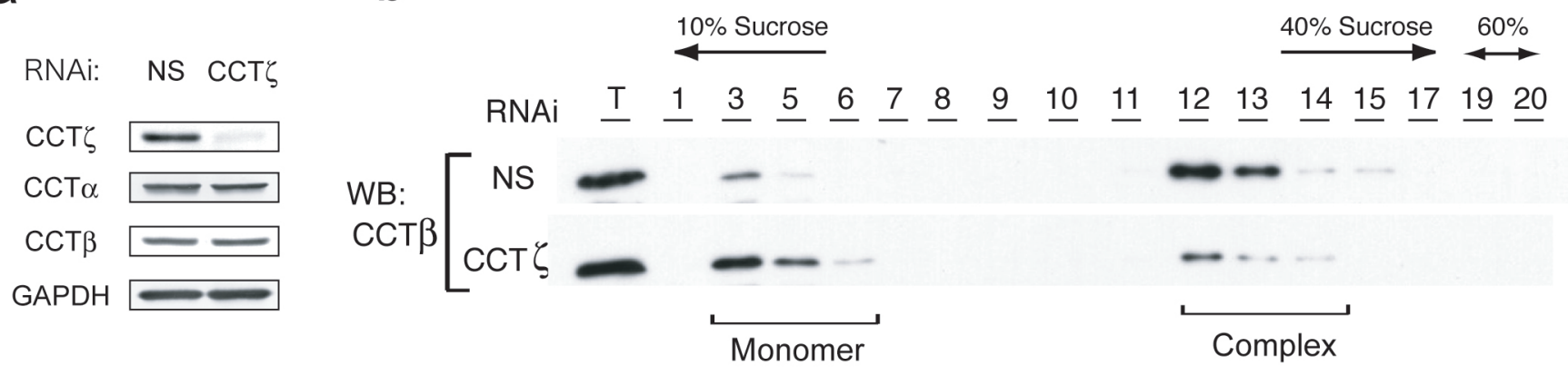



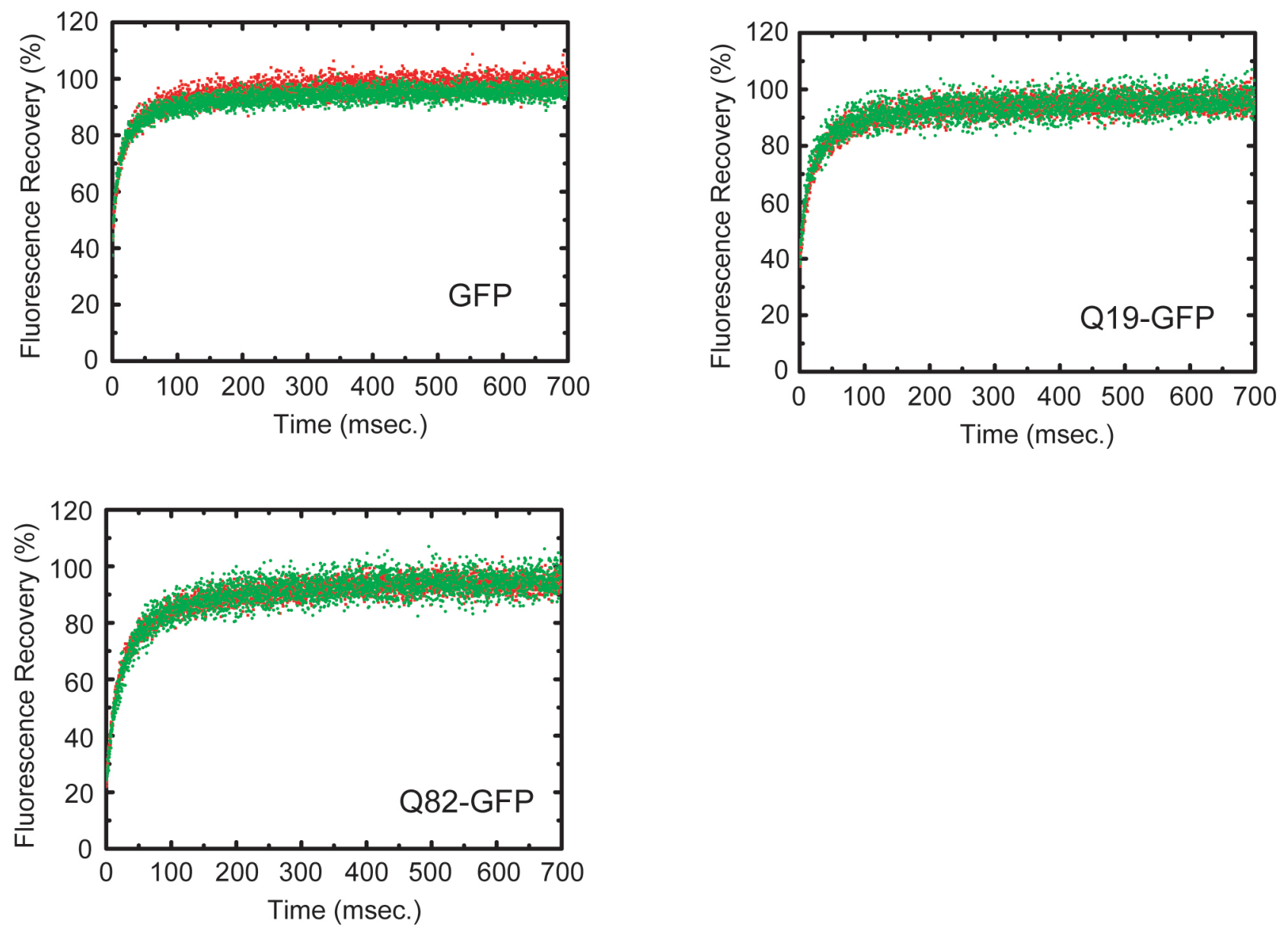

b
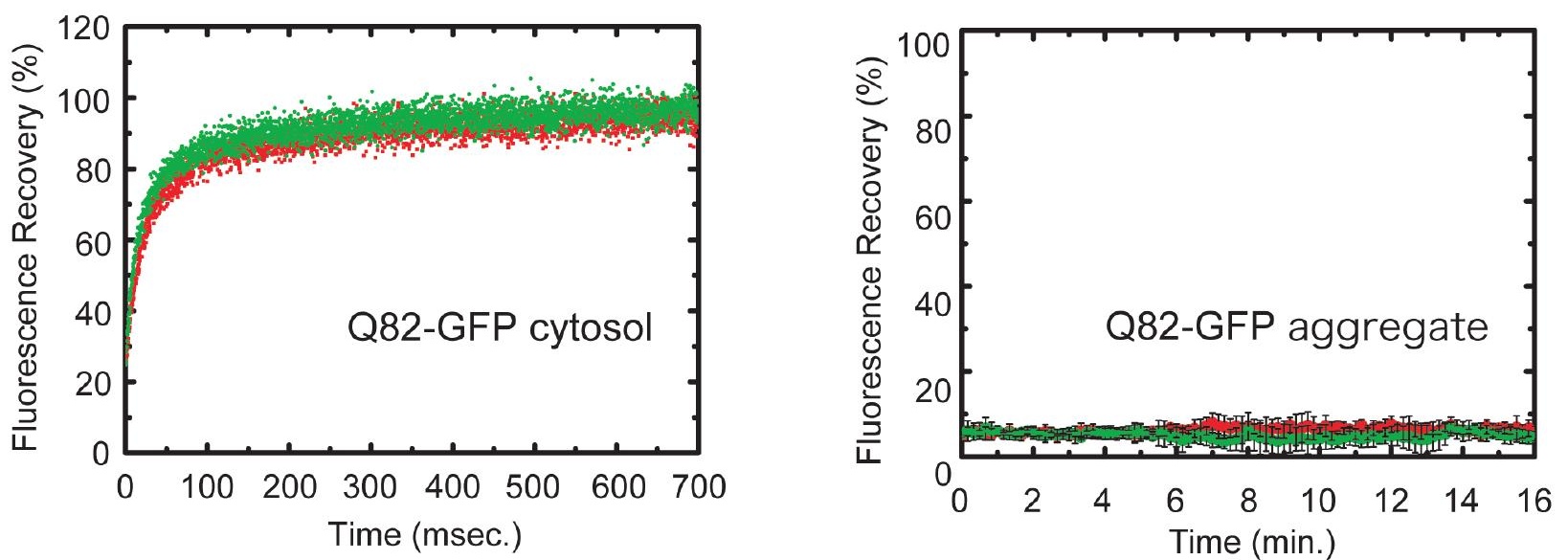


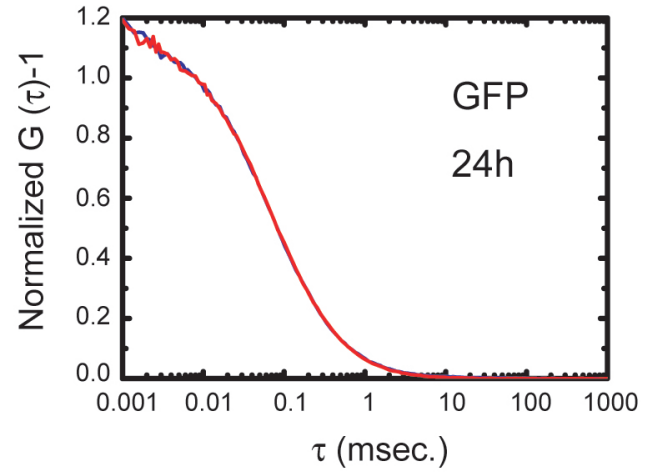

b
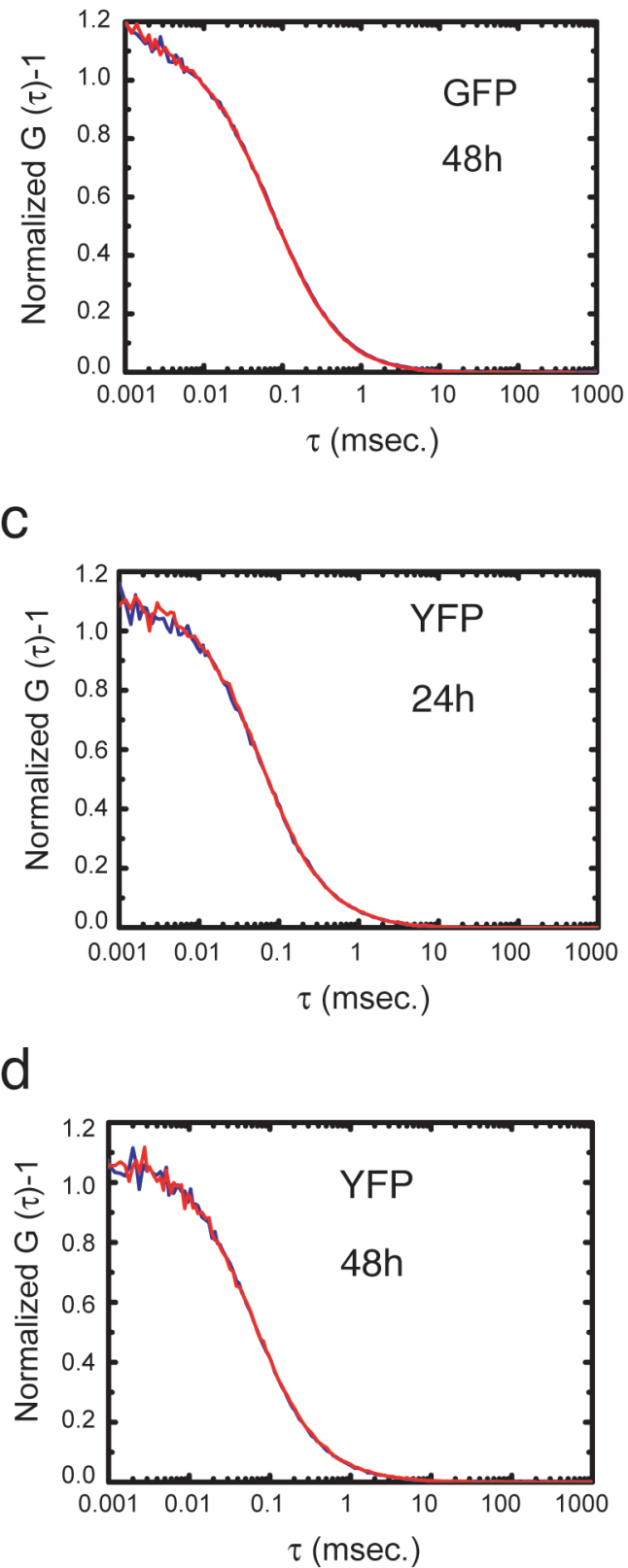

$\mathrm{d}$
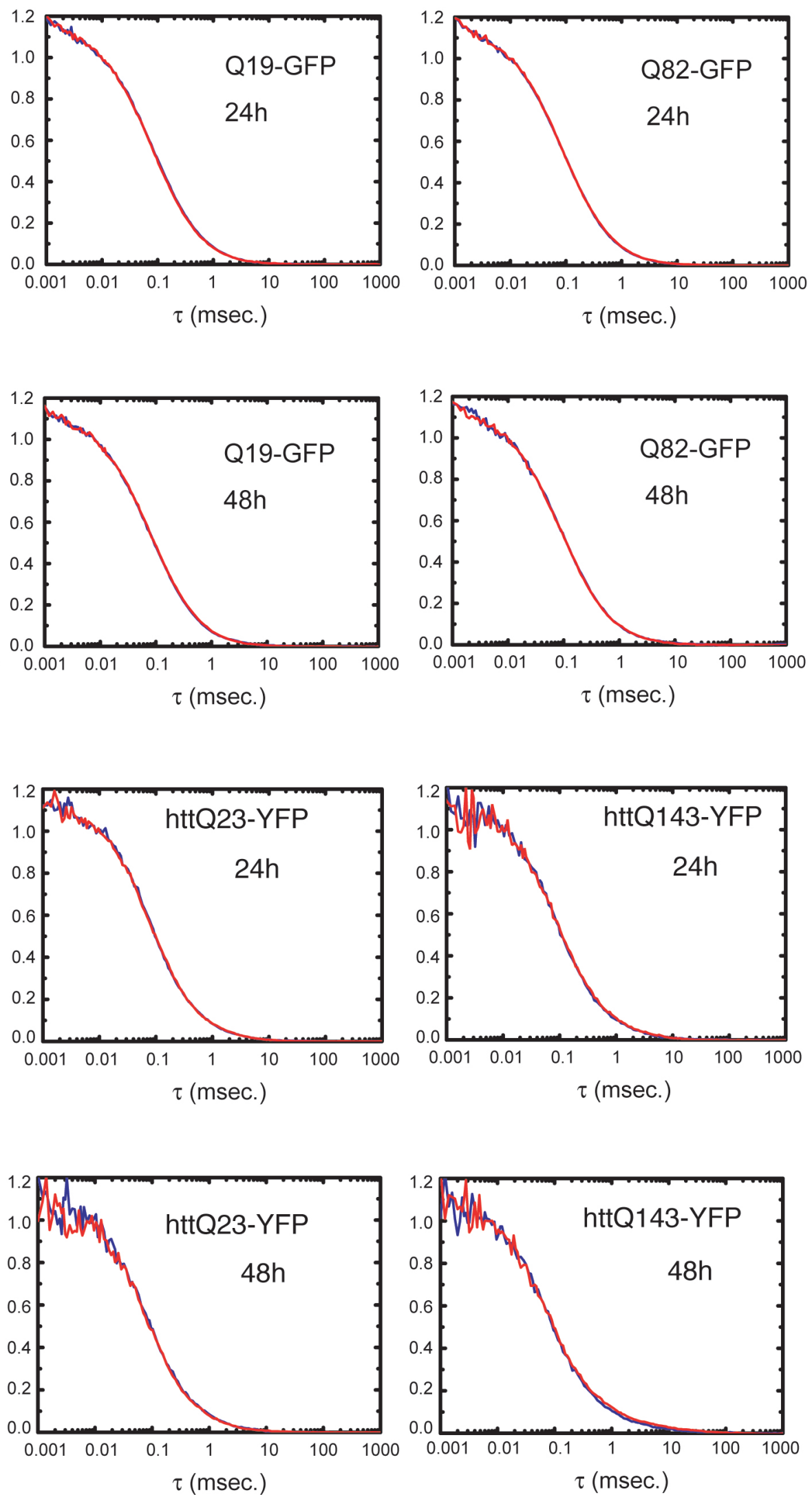
Full scans of Fig. 1a

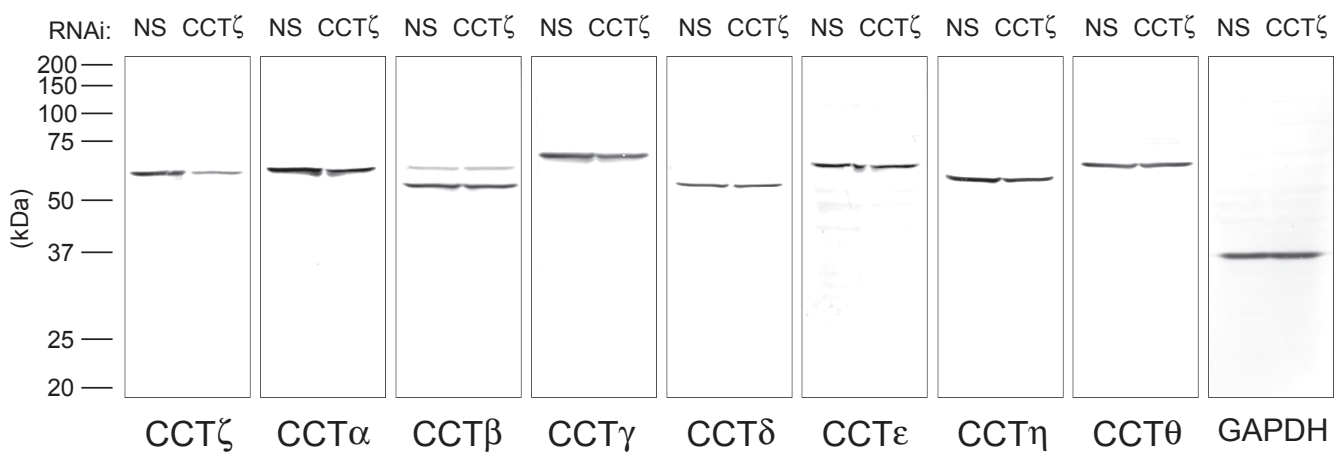

Full scans of Fig. 1b

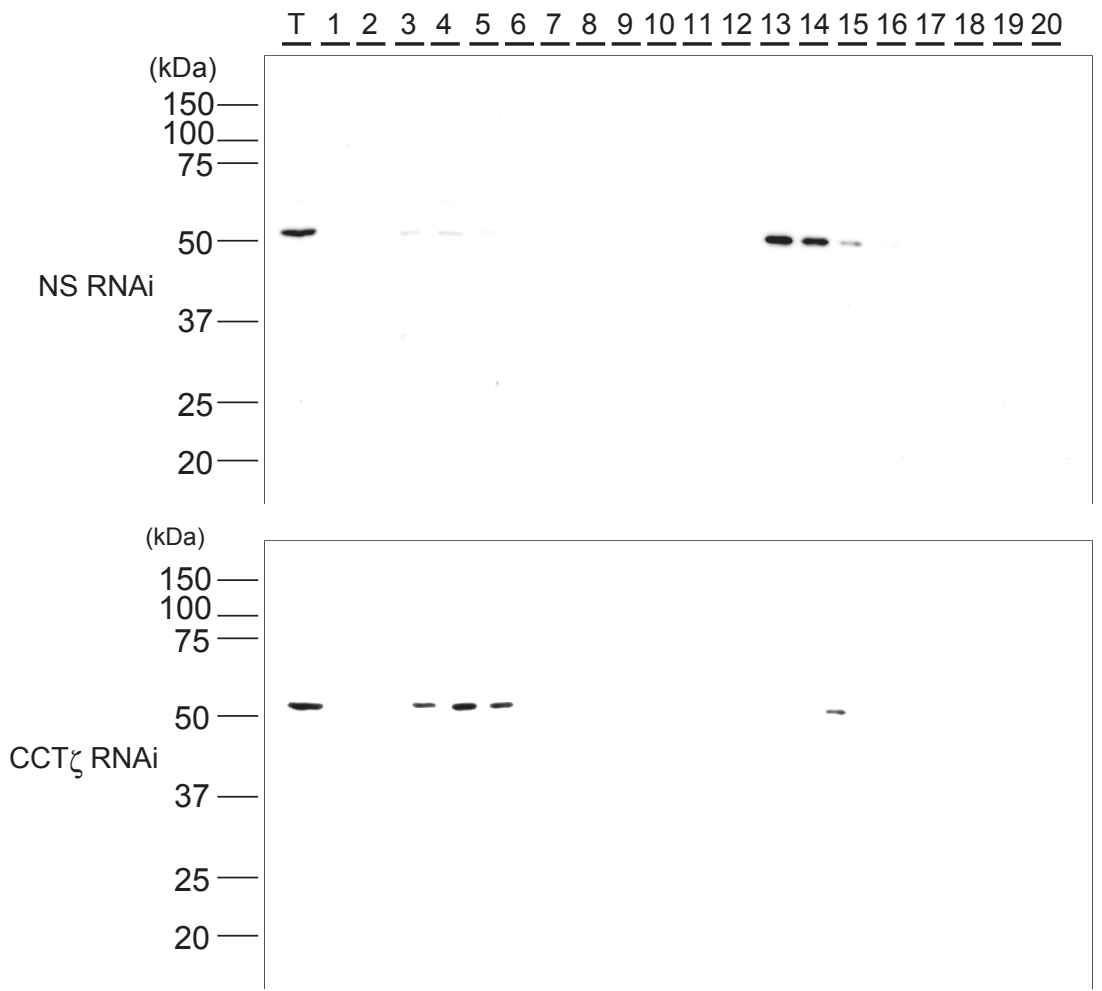

Full scans of Fig. 4e

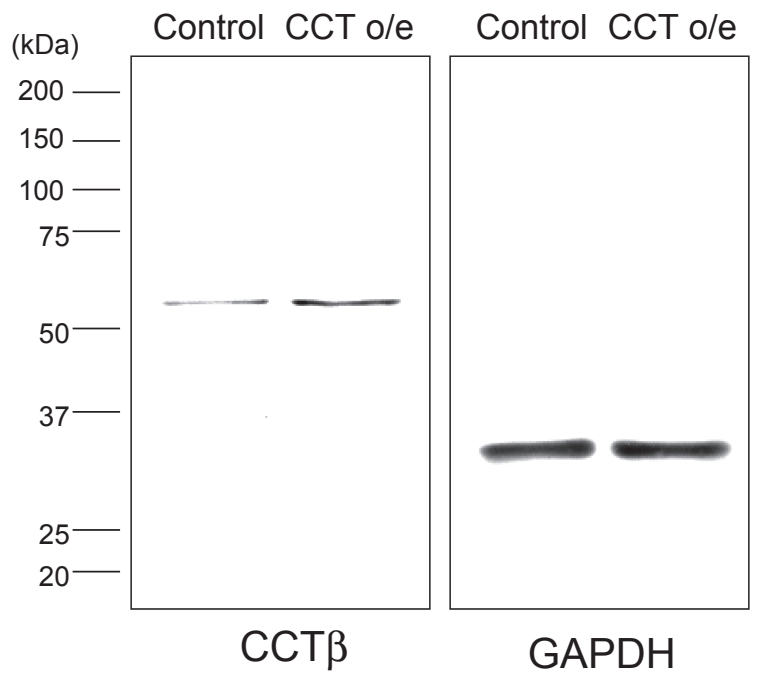

Full scans of Fig. $4 f$

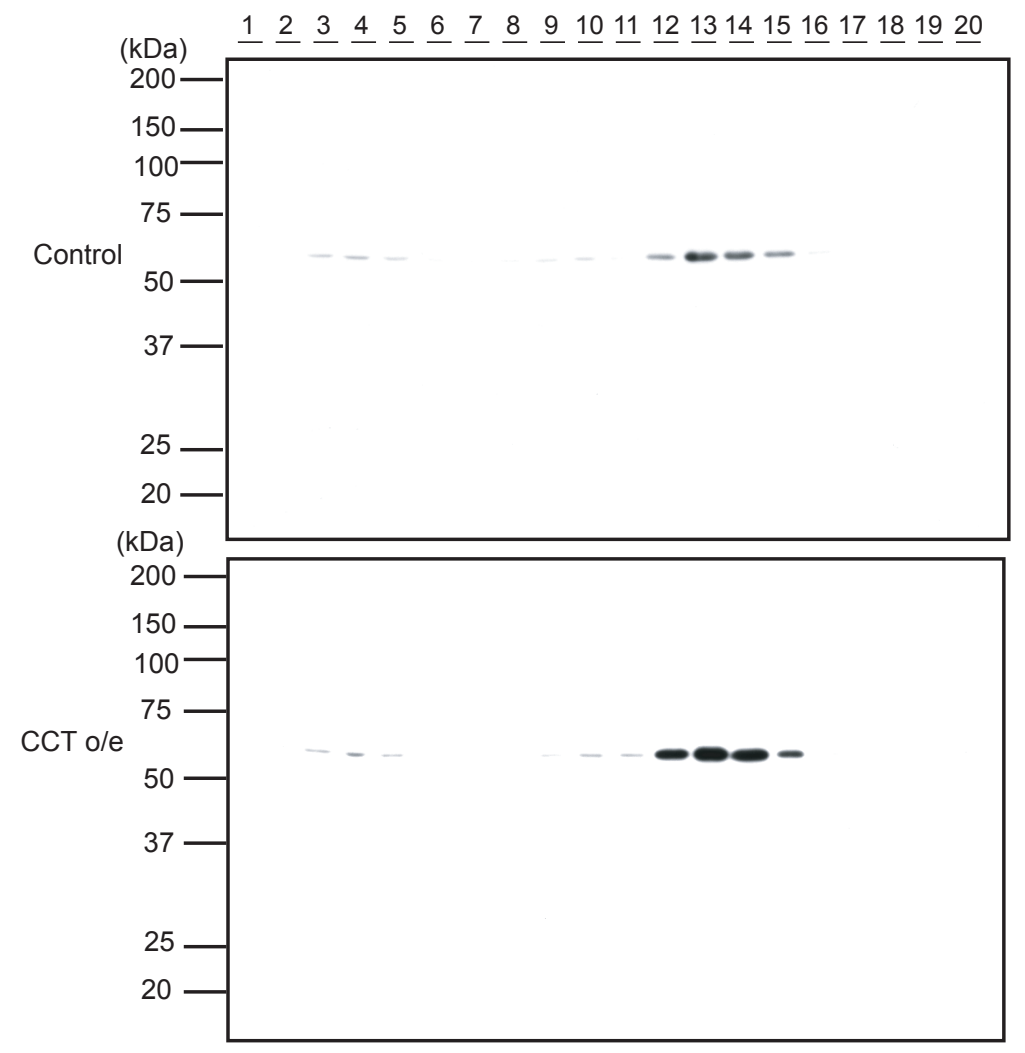

